UDC 613.65: 613.6.027

DOI: $10.21668 /$ health.risk/2020.3.18.eng

Research article

\title{
UP-TO-DATE TECHNIQUES FOR EXAMINING SAFETY AND PHYSIOLOGICAL EFFICIENCY OF INDUSTRIAL EXOSKELETONS
}

\author{
A.M. Geregei ${ }^{1}$, E.S. Shitova ${ }^{1}$, I.S. Malakhova ${ }^{1}$, E.S. Shuporin ${ }^{1}$, \\ E.V. Bondaruk ${ }^{1}$, A.R. Efimov ${ }^{2,3}$, V.Kh. Takh ${ }^{2}$
}

${ }^{1}$ Izmerov's Research Institute of Occupational Health, 31 Budennogo Ave., Moscow, 105275, Russian Federation

${ }^{2}$ Public Joint Stock Company «Sberbank of Russia», 19 Vavilova Str., Moscow, 117997, Russian Federation

${ }^{3}$ National University of Science and Technology «MISIS», 4 Leninskii Ave., Moscow, 119049, Russian Federation

Occupational morbidity caused by physical overloads and certain organs and systems being overstrained ranks second among occupational pathologies depending on an influencing adverse occupational factor. Given that, it seems vital and promising to develop industrial exoskeletons as they are able to protect a worker's musculoskeletal system from excessive physical loads. And absence of a relative regulatory and technologic base is a challenge here as it imposes substantial limitations on industrial exoskeletons implementation in productions both in Russia and in other countries.

A significant role in creating regulatory and technological base belongs to a possibility to accomplish an objective medical and biological examination of industrial exoskeletons safety and physiological efficiency. Developed and properly tested procedures for examining physiological and ergonomic properties of industrial exoskeletons will make a substantial contribution into a system of complex ergonomic tests accomplished at stages when exoskeletons are developed, created, and put into trial operation.

The present paper dwells on up-to-date medical and biological procedures for examining safety and physiological efficiency of industrial exoskeletons. There are examples on using a «movement seizure» procedure performed with inertial sensors, ergospirometry, electromyography, and myotonometry for estimating physiological and ergonomic properties of industrial exoskeletons at a modeled working place.

Results obtained via this research involving all the above mentioned procedures confirmed that it was safe and quite efficient to apply industrial exoskeletons for workers who had to deal with physical labor when performing work tasks similar to those used in developed models. Applied procedures can substantially enhance approaches to examining a worker's functional state and obtained results will make a significant contribution into development of a regulatory and technological base for promising individual protection means used to protect the musculoskeletal system within the existing System of occupational safety standards.

Key words: industrial exoskeletons, individual protection means, biomechanical analysis of movements, ergospirometry, electromyography, myotonometry.

(C) Geregei A.M., Shitova E.S., Malakhova I.S., Shuporin E.S., Bondaruk E.V., Efimov A.R., Takh V.Kh., 2020

Andrei M. Geregei - Head of the Laboratory for Individual Protection Means and Exoskeletons (e-mail: ppe-lab@irioh.ru; tel.: +7 (925) 083-25-55; ORCID: https://orcid.org/0000-0002-7927-2505).

Evgeniya S. Shitova - Junior researcher at the Laboratory for Individual Protection Means and Exoskeletons (e-mail: shitova.zhe@gmail.com; tel.: +7 (996) 441-85-09; ORCID: https://orcid.org/0000-0002-4379-5187).

Inga S. Malakhova - Junior researcher at the Laboratory for Individual Protection Means and Exoskeletons (e-mail: malahova.is@mail.ru; tel.: +7 (981) 784-07-29; ORCID: https://orcid.org/0000-0002-3215-3517).

Evgenii S. Shuporin - Junior researcher at the Laboratory for Individual Protection Means and Exoskeletons (e-mail: doctorshuporin@gmail.com; tel.: +7 (910) 481-34-38; ORCID: https://orcid.org/0000-0001-7590-431X).

Evgeniya V. Bondaruk - Junior researcher at the Laboratory for Individual Protection Means and Exoskeletons (e-mail: evegena@gmail.com; tel.: +7 (926) 826-56-63; ORCID: https://orcid.org/0000-0003-3762-0636).

Al'bert R. Efimov - Vice-president and Director of the Department for Research and Innovations of Russia», Senior lecturer at Engineering Cybernetics Department (e-mail: arefimov@sberbank.ru; tel.: +7 (916) 188-18-11; ORCID: https://orcid.org/00000001-6857-8659).

Vladimir Kh. Takh - Supervisor at the Robot Techniques Center (e-mail: sugggar@yandex.ru; tel.: +7 (929) 237-37-76; ORCID: https://orcid.org/0000-0002-9611-2992). 
Occupational morbidity caused by physical overloads and certain organs and systems being overstrained ranked $2^{\text {nd }}$ among occupational pathologies in 2018 depending on an influencing harmful occupational factor and amounted to $24.7 \%{ }^{1}$. And at present there are no personal protective equipment (PPE) that can prevent negative effects produced by labor hardness on a worker's musculoskeletal system (MSS). Given that, it seems promising to implement industrial exoskeletons (IE) that can protect a worker's musculoskeletal system from overstrain caused by physical loads. World IE market is growing and a lot of enterprises are trying to implement them, both abroad [1, 3-5], and in the Russian Federation as well [7-9].

A major problem that imposes certain limitations on IE implementation at production facilities, both in Russia and abroad, is an absence of a proper regulatory and technological base with requirements to them [1].

At present, according to the Order by the Federal Technical Regulation and Metrology Agency No. 962 issued on May 21, 2020 «On organizing activities of the technical committee (TC) on standardization "Personal protective equipment" "a production committee (PC) 11 (Industrial exoskeletons) was created within the TC 320 structure. It was organized at Izmerov's Research Institute of Occupational Health (hereinafter called the Institute). The Institute, together with IE designers, large enterprises, and scientific and research organizations, is working out two draft national standards that regulate requirements to IE as a new type of MSS PPE; the work is being accomplished within the National Standardization Program for $2020^{2}$.
It is beyond any doubts that objective medical and biological assessment of IE plays a significant role in making conclusions on their safety and physiological efficiency. We analyzed up-to-date approaches to examining a person's functional state that are applied in occupational medicine, sport medicine, functional diagnostics, rehabilitation, and other spheres. Procedures selected for the present work included:

- «movement seizure» with inertial sensors as the most acceptable procedure for assessing biomechanics of movements in joints $^{3}$;

- ergospirometry (ESM) as a non-invasive procedure for complex assessment of the cardiorespiratory system state [1-11];

- electromyography (EMG) as a basic procedure for assessing bioelectrical muscle activity [11-16];

- myotonometry (MTM) as an up-to-date procedure for muscle tone assessment.

Besides, our research included conventional procedures that are widely used in clinical and preventive medicine such as dynamometry $^{4}$, stabilometry, mental and physiological testing, questioning, interviewing, as well as functional tests $[17,18]$.

Experts from the Institute, together with the Robotechnics Laboratory of Sberbank, «Poleznye roboty» LLC, and «Exoatlant» LLC, performed a scientific research work in order to examine safety and physiological efficiency of IE application. The most significant results are outlined in the present paper.

The research goal was to assess safety and physiological efficiency of industrial exoskeletons application in modeled work activities using up-to-date research techniques.

\footnotetext{
${ }^{1}$ On sanitary-epidemiologic welfare of the population in the Russian Federation in 2018: The State Report. Moscow, The Federal Service for Surveillance over the Consumer Rights Protection and Human Well-being Publ., 2019, 254 p. (in Russian).

${ }^{2}$ On approval of the National Standardization Program for 2020: The Order by the Rosstandart issued on November 01, 2019 No. 2612 (last edited on March 18, 2020). KonsultantPlus. Available at: http://www.consultant.ru/document/cons_doc_LAW_338715/ (08.06.2020) (in Russian).

${ }^{3}$ A procedure for assessing ergonomic properties of different components in individual armor equipment of military personnel: patent No. RU2671187C1, A61B 5/103. No. 2017144762; declared on December 19, 2017; published on October 29, 2018. Bulletin No. 31, 24 p. (in Russian).

${ }^{4}$ State Standard GOST 12.4.061-88. The Occupational Safety Standards System (OSSS). The procedure for determining a person's working capacity in individual protection means. KODEKS: an electronic fund for legal and reference documentation. Available at: http://docs.cntd.ru/document/1200012620 (08.06.2020) (in Russian).
} 


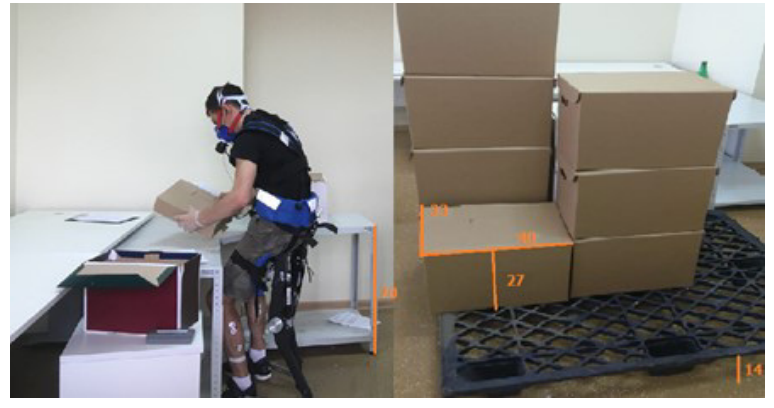

$a$

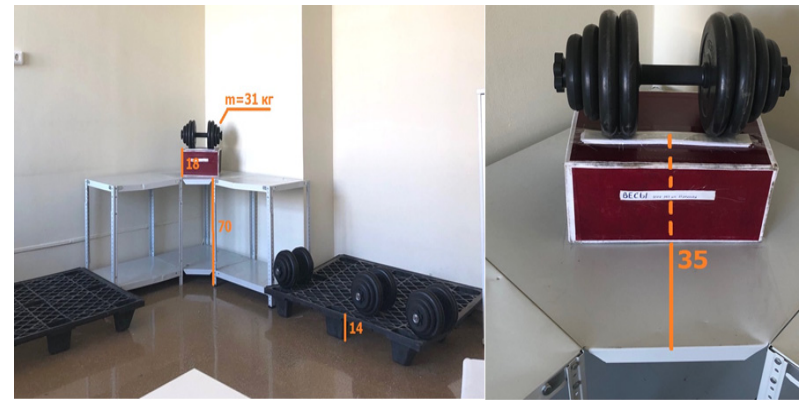

$b$

Figure 1. Workplaces models created in a laboratory:

a) shows a workplace of a logistician; b) shows a workplace of a cashier

Data and methods. Work activities models were developed in laboratories of the Institute basing on labor hardness parameters and characteristics of working postures and movements taken and made by workers with two occupations:

- a logistician working in Sberbank archives and logistics center;

- a cashier working in the precious metals department of Sberbank Main Cash Center.

To model work activities, we created working conditions identical to those existing at workplaces of a logistician working in Sberbank archives and logistics center and a cashier working in the precious metals department of Sberbank Main Cash Center.

Figure 1 shows models of workplaces belonging to workers with the above-mentioned occupations.

We tested the following IE samples: «Exochair» IE produced by «Poleznye roboty» LLC to reduce negative effects produced by static load on the musculoskeletal system of workers dealing with physical labor and having to work standing upright; and «ExoAtlant» («Exoatlant» LLC) made to reduce negative effects produced by dynamic load related to lifting weights and body bending.

Our volunteers were 6 healthy men (aged $27.8 \pm 4.8, \quad 183.0 \pm 5.8 \mathrm{~cm}$ high, with body weight equal to $80.0 \pm 11.1 \mathrm{~kg}$ and body mass index equal to $23.3 \pm 2.8$ ). Prior to the research they were examined by medical experts and were verified to be "healthy" by results of examinations as well as functional and laboratory tests. Each volunteer accomplished modeled work tasks both using an IE and without it.

Safety of IE application was assessed by:

- dynamics of volunteers' overall functional state;

- an extent to which amplitudes of active movements in large joints in the arms and legs and the vertebral column were limited due to IE application.

Physiological efficiency of IE application was assessed by:

- dynamics of energy expenditure borne by volunteers over the total amount of time during which work activities were modeled;

- cardio-respiratory system parameters;

- fatigue of skeletal muscles that participated in maintaining working postures and making movements necessary to accomplish a work task;

- parameters of volunteers' static coordination;

- subjective feelings and psychophysiological state of volunteers;

- labor productivity.

Overall functional state was assessed via an examination by a physician that included external examination, measurement of basic functional parameters, subjective assessment by a volunteer regarding his feelings during making voluntary movements in large joints and vertebral column, interviewing volunteers in order to reveal whether they had unpleasant feelings or pain (assessed with a 10-score scale), subjective assessment by volunteers regarding their functional state and working capacity.

In order to determine to what extent amplitudes of active movements in large joints in 
the arms and legs and the vertebral column were limited due to IE application, we used «Biomechanics Trust-M» system for complex objective assessment of movement functions, movement biomechanics registration, and EMG («Neurocor» LLC, Moscow, Russia). Inertial sensors were applied to register amplitudes of active movements in large joints in the arms and legs and the vertebral column.

To determine energy expenditure borne by volunteers, we applied «Metamax 3B» portable complex for ESM testing (Cortex, Germany) and Polar $\mathrm{H} 10$ heart rate monitor with elastic belt (Polar Electro, Finland). Gas exchange parameters were registered automatically during work shift modeling.

To assess influence exerted by IE on volunteers' cardio-respiratory system, we applied Ruffier test, Physical Working Capacity 170 test, Stange-Hench test, Serkin's test, as well as active stand test.

Skeletal muscles fatigue was assessed with EMG using «Biomechanics Trust-M» system for complex objective assessment of movement functions, movement biomechanics registration, and EMG (with «Myoton PRO» device («Myoton AS», Estonia)), as well as hand and backbone dynamometry.

When examining physiological efficiency of «Exochair» IE application, we assessed functional state of muscles in the back and legs of a volunteer who was standing still (EMG) or lying (MTM); for «ExoAtlant» IE efficiency, we assessed functional state of muscles in the back and arms beyond modeled work activities (EMG) in two postures taken by a volunteer (standing and holding $31 \mathrm{~kg}$; standing in a working posture with the same weight but using an IE); we also measured muscle tone of erector spine muscle when a volunteer took a working posture carrying some weight (MTM). Besides, we applied hand and backbone dynamometry.

To assess volunteers' static coordination, we applied «Stabilometry Trust-M» platform included into a treatment set for treating and rehabilitating patients with movement pathologies («Neurocor» LLC. Moscow, Russia). We applied Romberg's test with eyes open and closed as a test that allowed assessing functional state of the postural system.

Volunteers' psychophysiological state was determined with UPDK-MK universal psycho-diagnostic complex («Neurocom» LLC, Moscow). We applied an express test for functional state assessment, «Complex motor reaction» test, and "Critical flicker frequency» test, and tapping test. Besides, after all the tests volunteers filled in questionnaires in order to assess exoskeletons' ergonomic properties.

When examining efficiency of «Exochair» IE application, we assessed labor productivity dynamics. As a major task performed by a logistician working in Sberbank archives and logistics center is to find documents kept in boxes that he or she has to move, we took a number of documents found over a certain period of time as a performance indicator. When examining «ExoAtlant» IE efficiency, we modeled work activities in such a way so that loads on one volunteer were the same and constant during the whole working period; therefore, labor productivity was not assessed.

Each IE was examined in two stages. The $1^{\text {st }}$ stage involved work activities modeling without IE (the reference group). At the $2^{\text {nd }}$ stage work activities with IE application were modeled. Tests were accomplished prior to work activities modeling (background testing); during breaks (intermediate testing); after modeling (control testing); the tests were the same at both stages. Examination program for each work activities model is shown in Figures 2.

Test results obtained for different groups were comparatively analyzed both within groups and between them. All the results were statistically processed with Statistica 10.0 and MS Office Excel 2019 software packages.

Results and discussion. Most research procedures applied in this work including functional tests, dynamometry, stabilometry, and psychophysiological testing, yielded such results that in most cases there were no statistically significant differences between parameters registered for volunteers working without IE and with them. It is highly likely 


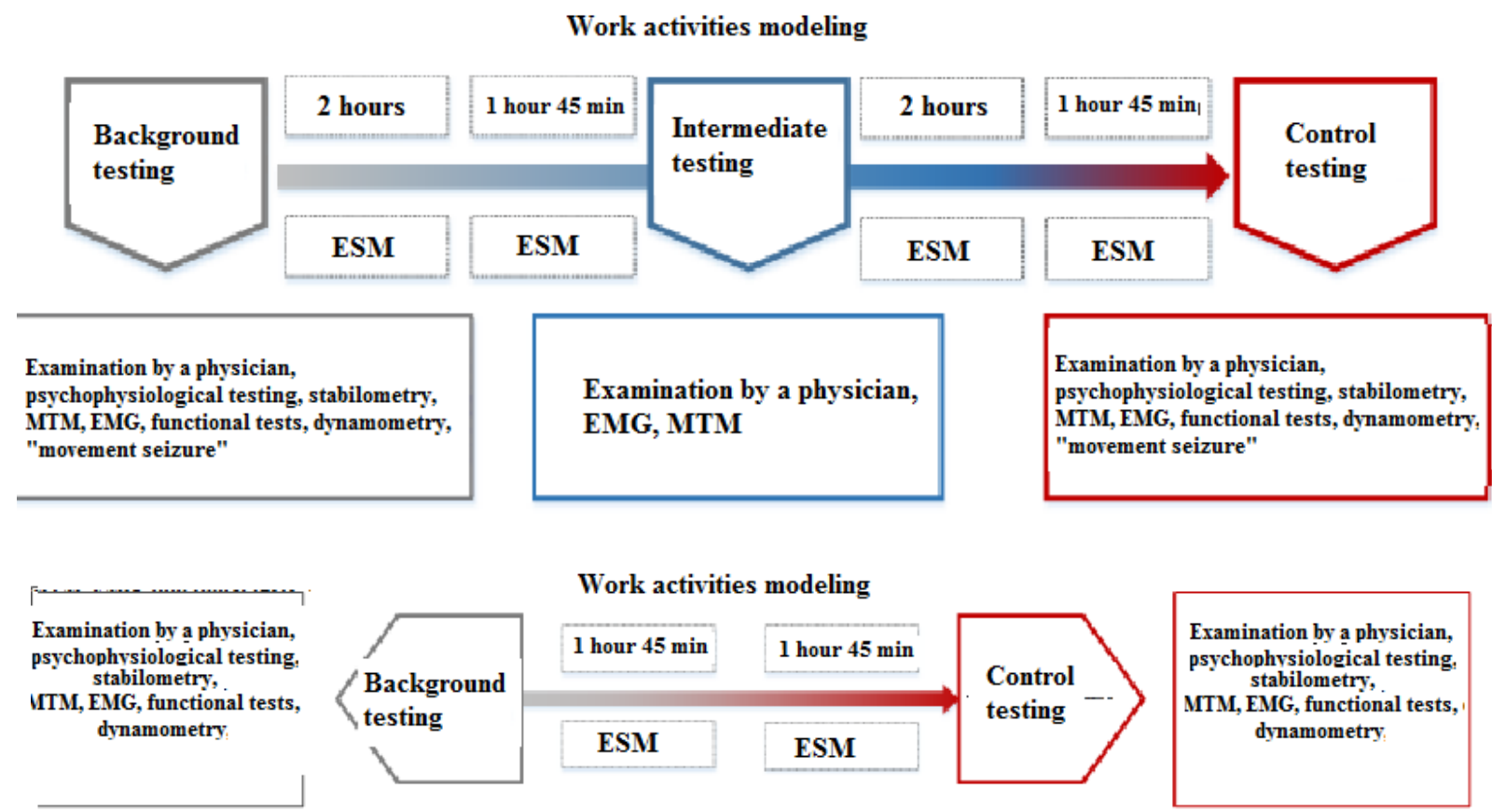

Figure 2. Examination program for a model showing work activities by a logistician working in Sberbank archives and logistics center («Exochair» IE examination) and a cashier working in the precious metals department of Sberbank Main Cash Center («ExoAtlant» IE examination)

that the fact is related to a small sampling, individual peculiarities of volunteers' bodies, and significant influence exerted by the conative component on testing results.

But still, volunteers who applied both examined IE in their work had their heart rate and blood pressure within reference values and being adequate to physical loads (just as in the reference group). Besides, when volunteers estimated movements in their large joints and vertebral column and answered questions during interviewing, their answers and estimations obtained during the whole period of work activities modeling allowed establishing that use of «ExoAtlant» IE didn't result in any pain or impose any limitations on amplitudes of active movements in the lumbar spine that occurred when the same work tasks were performed without IE. The above-mentioned can be considered as facts indicating that use of the examined IE was really safe and physiologically efficient.

We analyzed amplitudes of active movement in the lumbar spine and large joints in the arms and legs using inertial sensors; the analy- sis revealed a decrease in amplitudes of active movements almost in all the examined joints. Figures 3-5 show amplitudes of active movements in the legs and vertebral column in dynamics in case «Exochair» IE is applied.

As we can see, amplitudes of active movements in the lumbar-thoracic spine of volunteers who worked with «Exochair» IE decreased by $32 \%$ when they bent forward; by $7 \%$, when they bent to the left; $13 \%$, to the right; $33 \%$, when they turned right; $40 \%$, when they turned left; and $64 \%$ when they squatted.

«Exochair» IE application resulted in a decrease in amplitudes of active movements in the left and right hip joints, by $3 \%$ and $12 \%$ for unbending accordingly; squatting, by $67 \%$ and $64 \%$; when raising a leg bent at the knee, by $27 \%$ and $28 \%$ accordingly.

We detected that application of this IE led to a decrease in amplitudes of active movements in the left and right knee joints, by $54 \%$ and $56 \%$ accordingly for squatting; by $34 \%$ and $41 \%$ accordingly, for raising a leg bent at the knee; by $47 \%$ and $53 \%$ accordingly for knee joint bending. 


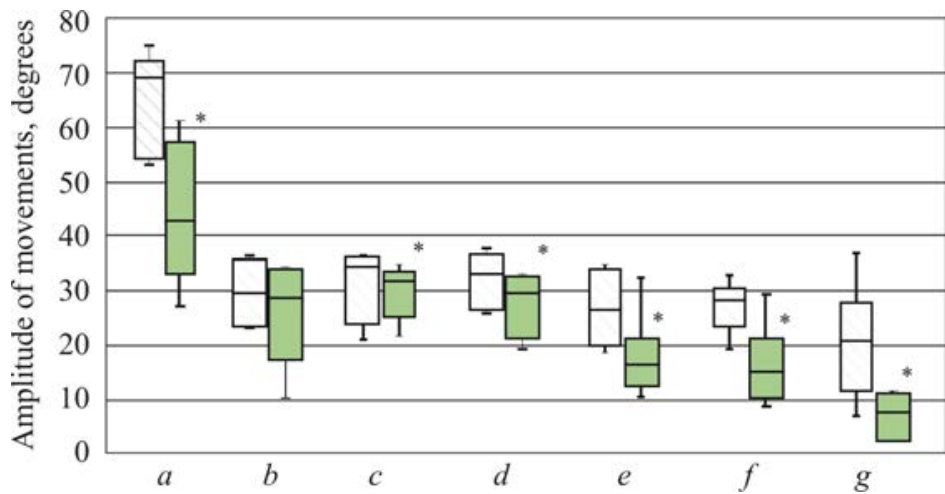

Figure 3. Amplitudes of active movements in the lumbar spine without «Exochair» IE $(\square)$ and with it $(\square), n=6$

Note: a means bending forward; $b$, backward; $c$, to the right; $d$, to the left; e, turning right; f, turning left; g, squatting;

* means discrepancies in the parameters are statistically significant in comparison with the reference group $(p \leq 0.05)$
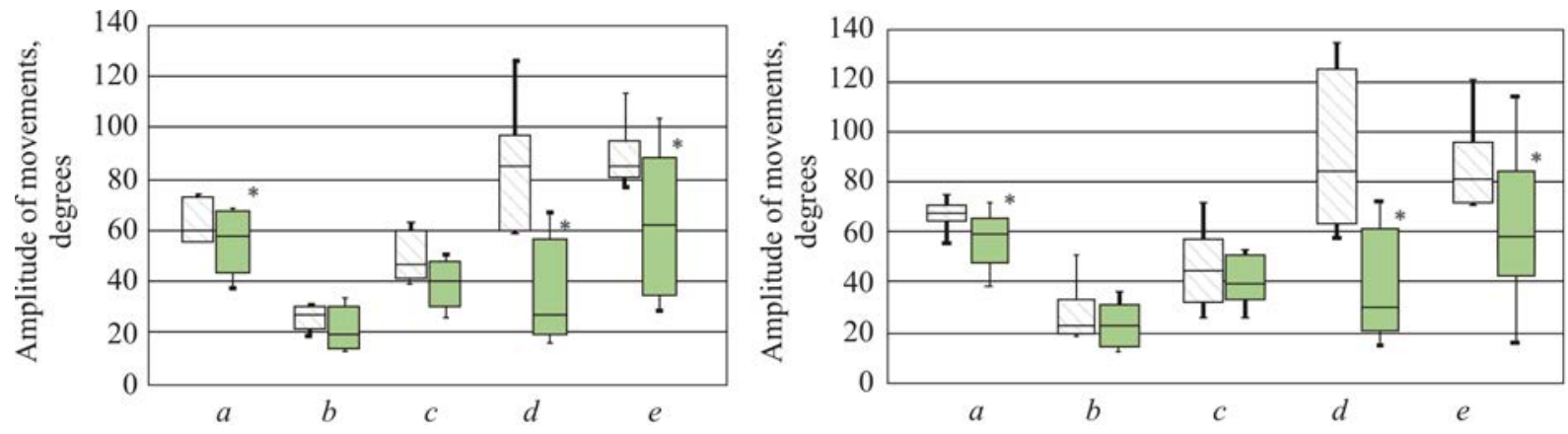

Figure 4. Amplitudes of active movements in the left (left) and right (right) hip joints without «Exochair» IE ( $\square)$ and with it $(\square), n=6$

Note: a means bending; b, unbending; c, abduction; d, squatting; e, raising a leg;

* means discrepancies in the parameters are statistically significant in comparison with the reference group $(p \leq 0.05)$
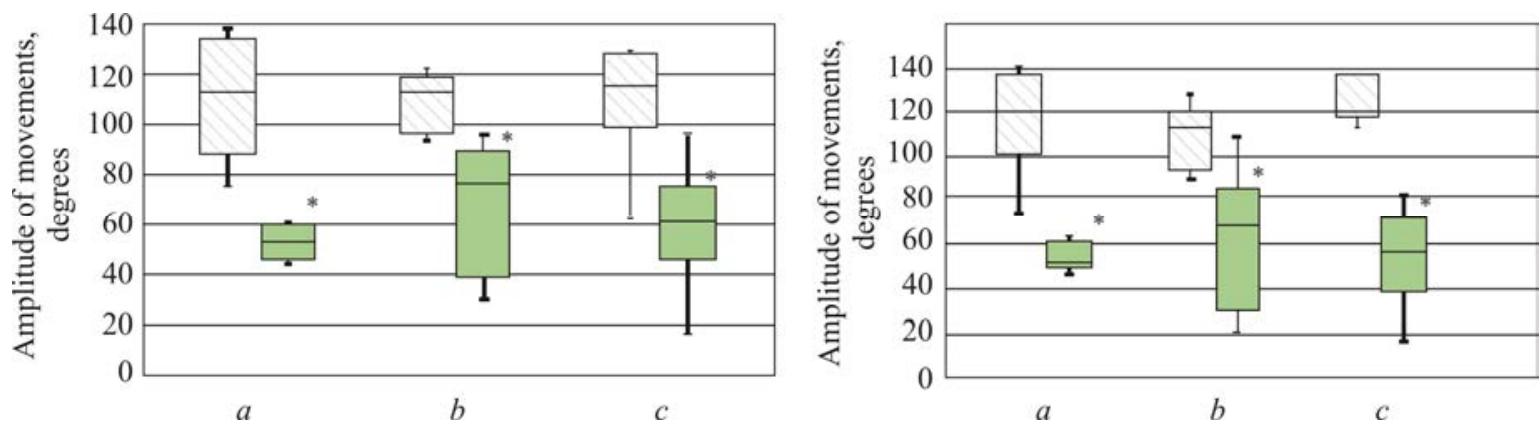

Figure 5. Amplitudes of active movements in the left (left) and right (right) knee joints without «Exochair» IE ( $\square$ ) and with it $(\square), n=6$

Note: a means squatting; b, raising a leg bent at the knee; $c$, knee joint bending;

* means discrepancies in the parameters are statistically significant in comparison with the reference group $(p \leq 0.05)$ 
Figures $6-8$ show data indicating that there are certain limitations imposed on amplitudes of active movements in the lumbar-thoracic spine, hip and knee joints by «ExoAtlant» IE application.
We determined that amplitudes of active movements in the lumbar-thoracic spine went down by $55 \%$ when a volunteer using «ExoAtlant» IE turned right and by $54 \%$ when he turned left.

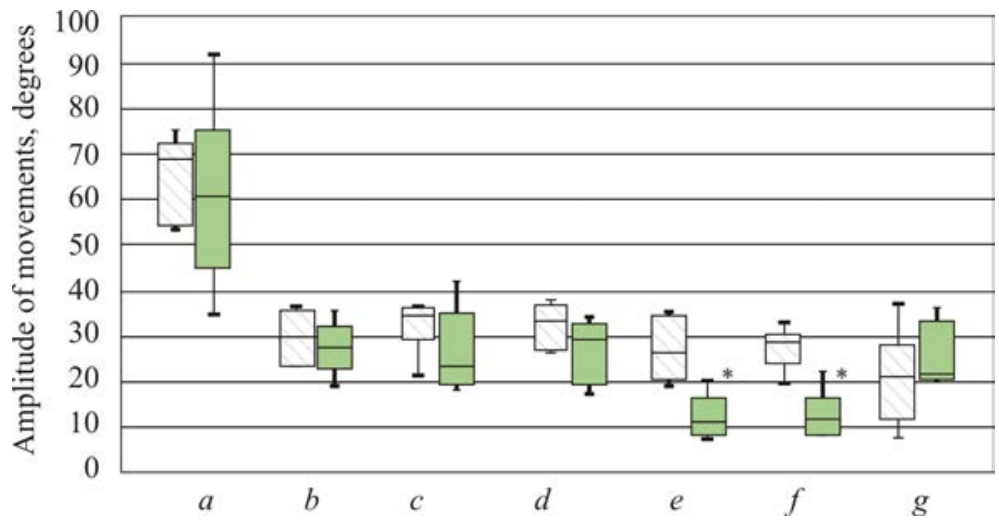

Figure 6. Amplitudes of active movements in the lumbar spine without IE $(\square)$ and with it $(\square), n=6$

Note: a means bending forward; b, backward; c, to the right; $d$, to the left; e, turning right;

f, turning left; g, squatting;

* means discrepancies in the parameters are statistically significant in comparison with the reference group $(p \leq 0.05)$
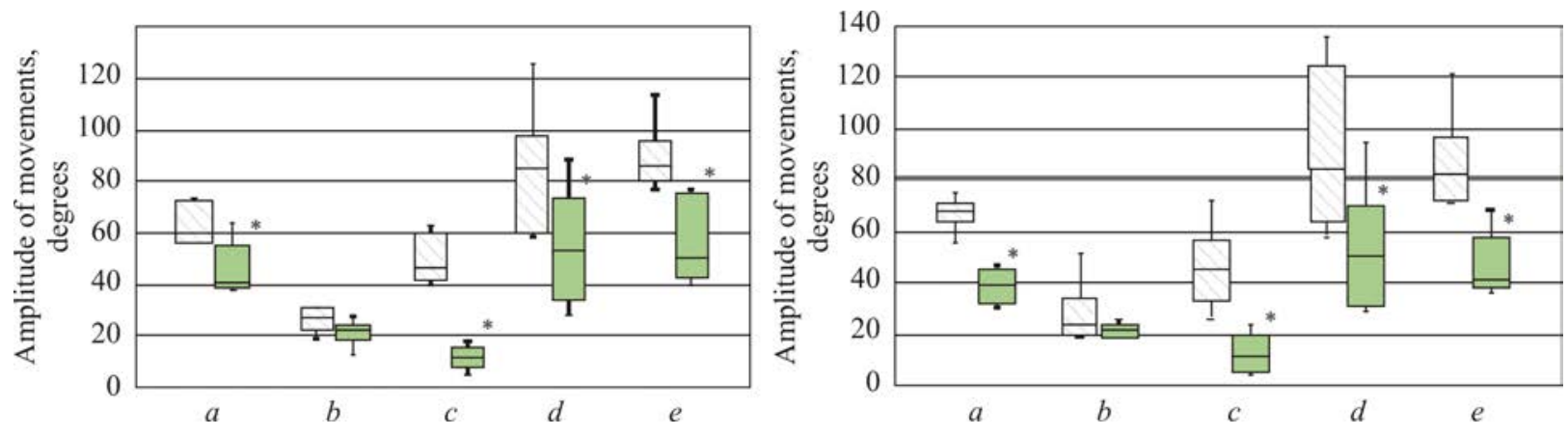

Figure 7. Amplitudes of active movements in the left (left) and right (right) hip joints without «ExoAtlant» IE ( $\square$ ) and with it $\square$, $n=6$

Note: a means bending; b, unbending; c, abduction; $d$, squatting; e, raising a leg;

* means discrepancies in the parameters are statistically significant in comparison with the reference group $(p \leq 0.05)$
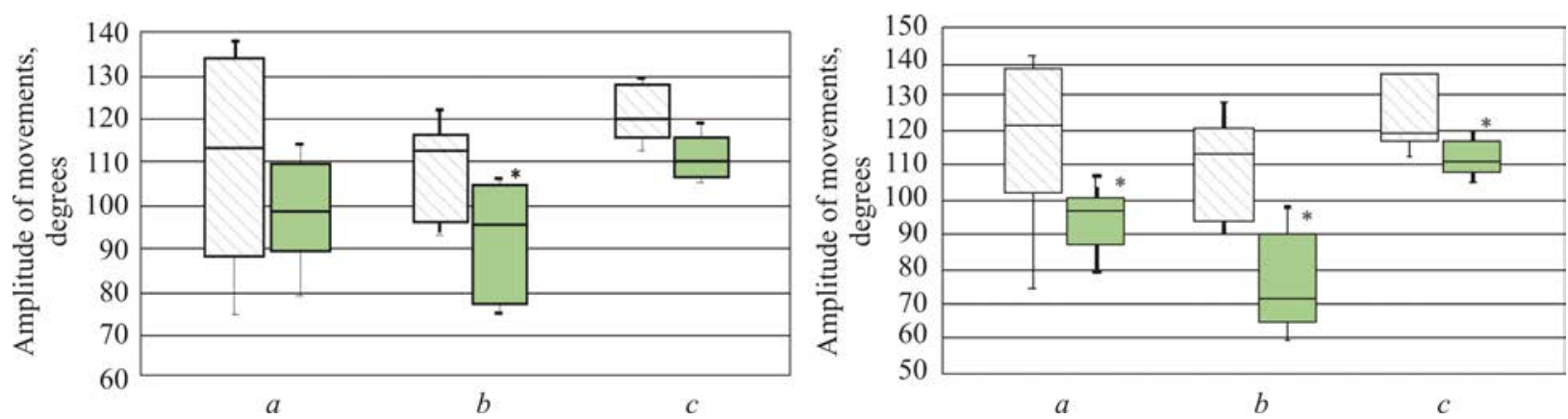

Figure 8. Amplitudes of active movements in the left (left) and right (right) knee joints without «ExoAtlant» IE ( $\square$ ) and with it $(\square), n=6$

Note: a means squatting; $b$, raising a leg bent at the knee; $c$, knee joint bending;

* means discrepancies in the parameters are statistically significant in comparison with the reference group $(p \leq 0.05)$ 
Amplitudes of active movements in the left and right hip joints went down due to «ExoAtlant» IE application by $32 \%$ and $41 \%$ accordingly when they were bent; by $74 \%$ and $73 \%$, when abducted; by $3 \%$ and $39 \%$ when a volunteer squatted; and by $41 \%$ and $49 \%$ accordingly when a volunteer raised a leg bent at the knee.

«ExoAtlant»IE application led to a decrease in amplitudes of active movements: by $20 \%$ in the right knee joint when a volunteer squatted; by $38 \%$, when he bent the knee; and by $16 \%$ in the left knee joint when a volunteer raised a leg bent at the knee.

The detected limitations on vertebral joints and joints in the legs in volunteers performing their work tasks with IE application allowed us to outline how important it was to be cautious when applying IE at industrial objects, especially when it comes to workers who have to perform work tasks involving a lot of movements with wider amplitudes.

We performed comparative analysis of energy expenditure borne by volunteers with IE and without them; in our opinion, its results are the most important for assessing physiological efficiency of IE application as they revealed a statistically significant decrease in energy expenditure borne by volunteers; it amounted to $5 \%$ and $7 \%$ accordingly for 6 and 8 hours of work activities in a situation when «Exochair» IE was applied (Figure 9 and 10).

We should note that, together with a decrease in energy expenditure borne by volunteers when they performed their work tasks, volunteers' labor productivity had statistically significant growth almost at each hour of work activities modeling (Figure 10). Thus, a number of documents, a volunteer managed to find increased by $13-38 \%$ at $1-7$ hours of work.

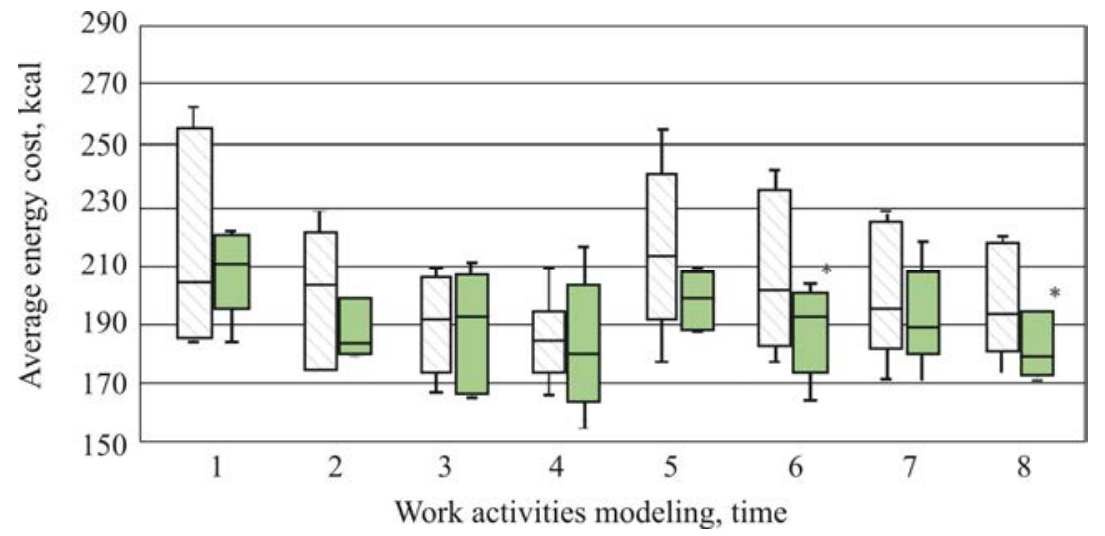

Figure 9. Dynamics of energy expenditure borne by volunteers without «Exochair» IE $(\square)$ and with it $(\square), n=6$ Note: * means discrepancies in the parameters are statistically significant in comparison with the reference group $(p \leq 0.05)$

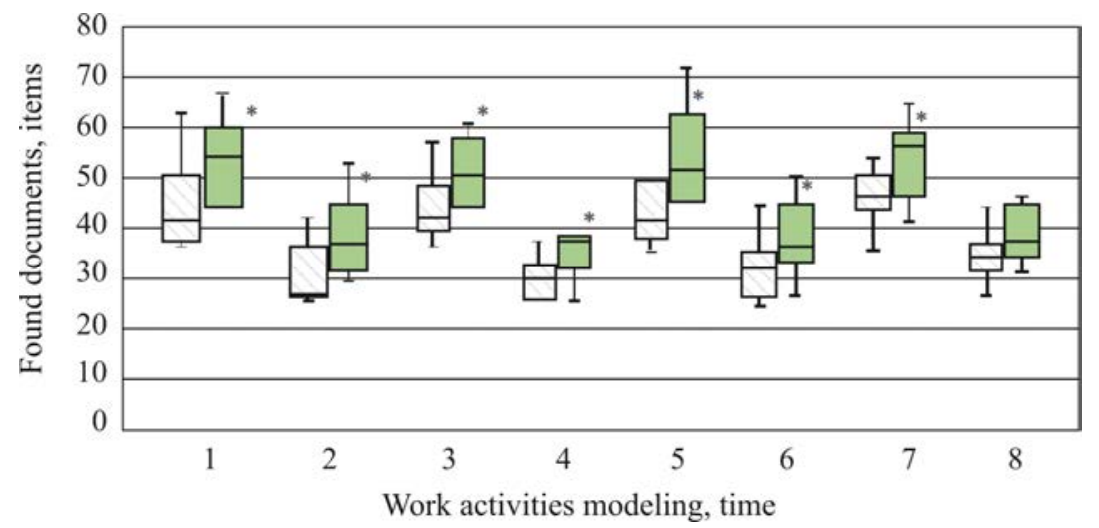

Figure 10. Dynamics of volunteers' labor productivity without «Exochair» IE $(\square)$ and with it $(\square), n=6$ Note: * means discrepancies in the parameters are statistically significant in comparison with the reference group $(p \leq 0.05)$ 
We detected certain changes when assessing fatigue of volunteers' musculoskeletal system. Thus, when examining «ExoAtlant» IE via EMT performed on a volunteer who was standing in a working posture with a load, we revealed a decrease in bioelectrical activity of the erector spine muscle, by $24 \%$ and $36 \%$ on the right and on the left accordingly, during tests with IE against parameters obtained during tests without IE. But at the same time, bioelectrical activity of the left biceps muscle of the arm was by $72 \%$ higher in volunteers who used IE against those from the reference group (Figure 11).

All the above mentioned changes allow us to conclude that there is a decrease in activity of the erector spine muscle as loads on it are reduced due to IE. And an increase in activity of the left biceps of the arm can indicate that loads are possibly redistributed from the spine to the arms.
We also performed MTM on volunteers who were lying at rest on a coach; control tests results revealed a statistically significant decrease in the tone of the lumbar section in the erector spine muscle, by $4 \%$ on the right and $3 \%$ on the left; the semitendinous muscle by $3 \%$ on the right; and the medial vastus thigh muscle on both sides (by $4 \%$ on the right and by $5 \%$ on the left) in volunteers who used «Exochair» IE against the background values (Figure 12). The detected changes can indicate that by the end of the work shift all these muscles were less strained than it was at the beginning of it. As there were no similar changes in the reference group, we can assume that use of «Exochair» IE reduces loads on certain muscles in the spine and thighs that participate in keeping working postures and performing movements required to fulfill work tasks.

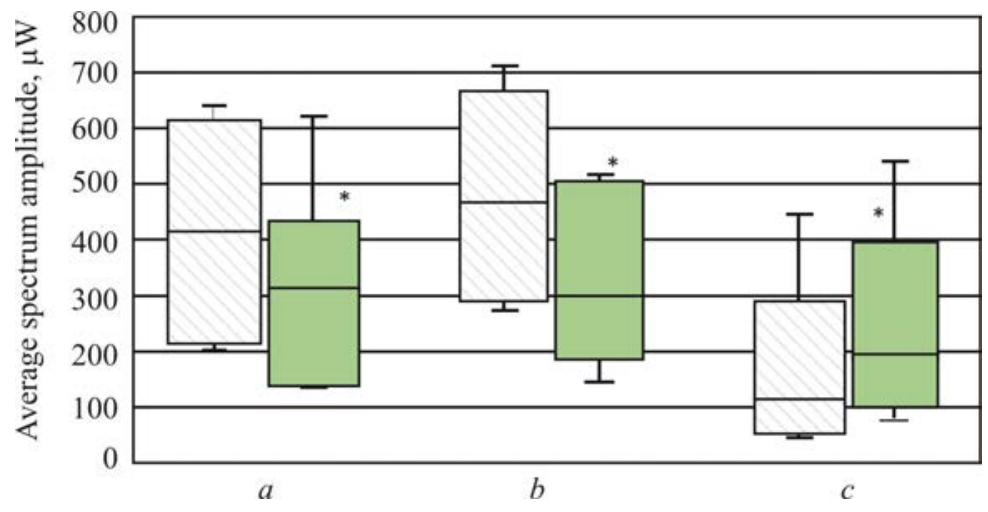

Figure 11. Bioelectrical activity of the electro spine muscle taken in dynamics: on the right (a) and on the left (b), and the left biceps muscle of the arm (c) in volunteers standing in a working posture with a load without «ExoAtlant» IE ( $\square$ ), and with it $(\square), n=6$

Note: * means discrepancies in the parameters are statistically significant in comparison with the reference group $(p \leq 0.05)$

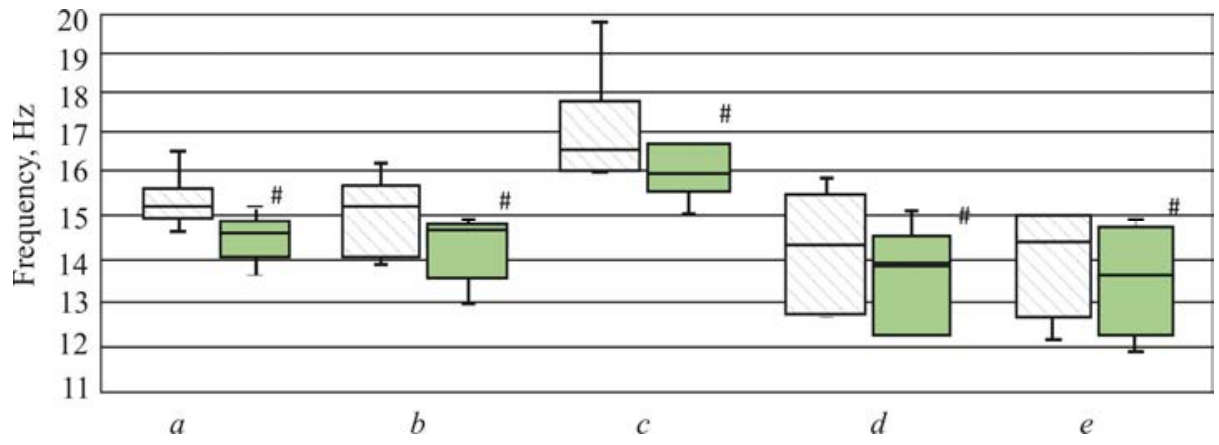

Figure 12. The tone in the illocostal muscle on the right (a) and on the left (b), semitendinous muscle (c), medial vastus thigh muscle on the right $(\mathrm{d})$ and on the left $(\mathrm{e})$ in volunteers who use «Exochair» IE prior to working activities modeling $(\square)$ and after it $(\square), n=6$

Note: \# means there are statistically significant discrepancies from the background values 


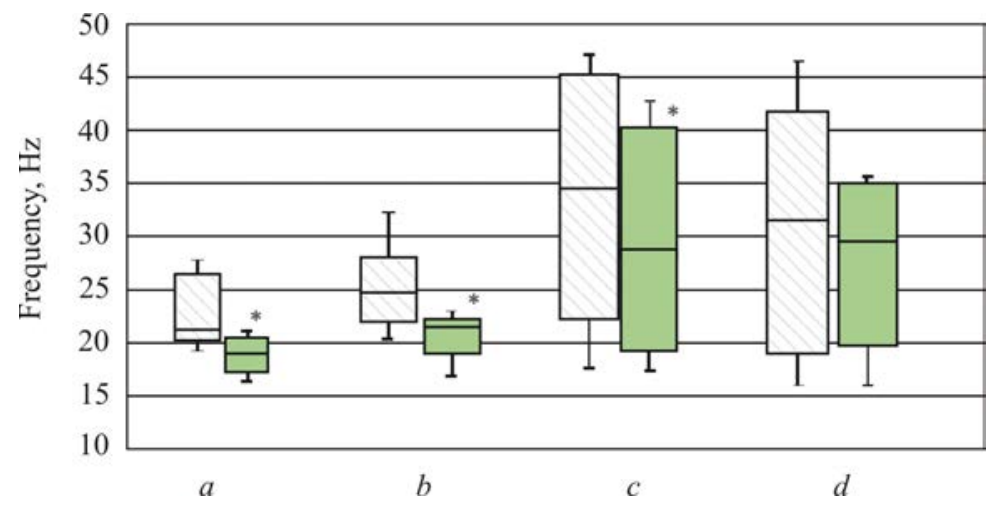

Figure 13. The tone of the longest breast muscle on the right (a) and on the left (b), illocostal muscle on the right (c) and on the left (d) prior to working activities modeling ( $\square$ ) and after it ( $\square$ ) in volunteers who use «ExoAtlant» IE, $n=6$

Note: \# means there are statistically significant discrepancies from the background values

Having performed MTM on the erector spine muscle during its maximum strain, especially when a volunteer was in a working posture and holding $31 \mathrm{~kg}$, we established that the tone of the longest breast muscle on the right and on the left as well as the illocostal muscle in the lumbar spine on the right were by $10 \%$, $13 \%$ and $17 \%$ lower after work was over than pior to its beginning in volunteers who used «ExoAtlant» IE during work; given that there were no similar changes in the reference group, we can assume that it indirectly indicates there is lower load on these muscles due to IE (Figure 13).

But still, taking into account peculiarities related to myotonometer functioning and caused by difficulties in measuring muscle tones that are either located rather deep or are small in size, absence of unified standards for measured parameters and substantial evidential base, as well as a procedure itself being an experimental one, further investigation is required regarding diagnostics of skeletal muscles fatigue in order to perform physiological and ergonomic assessment of IE using MTM.

Having analyzed questionnaires filled in by volunteers after working with «Exochair» IE, we established that they gave the highest evaluations to the following parameters: IE exterior; overall well-being during work with IE; and IE being quite helpful during work. In volunteers' opinion, there were also some disadvantages such as IE being difficult to put on/off; limited movements in it; a person feeling himself uncomfortable to move in it; IE being too heavy; a volunteer feeling himself uncomfortable when IE was put on.

«ExoAtlant» IE and its ergonomic characteristics got more favorable marks; volunteers mentioned nice exterior, proper size and weight; IE being easy to put on/off; ergonomic design providing comfortable position on a body; IE being easy to handle; overall wellbeing during work with IE and IE being quite helpful during work; absence of any negative feeling during work in the given IE. However, volunteers gave rather low evaluations to their ability to move in the IE and stated that the IE limited their movements just as it was with «Exochair» IE.

Obviously, all the listed properties of the examined IE can either raise or reduce overall strain during work and they can influence both workers' health and quality of their work. Consequently, further profound examinations and assessment of variable IE properties by workers who are to use them as well as longer periods of IE use during several working shifts will allow eliminating all the revealed drawbacks.

Conclusion. Contemporary approaches to determining a person's functional state including «movement seizure» using inertial sensors, ergospirometry, electromyography, and myotonometry allow performing objective medical and biological assessments whether it is safe and efficient to apply industrial exoskeletons in laboratory conditions.

Results obtained in the present research performed with all the above-mentioned procedures confirmed that it was safe and quite 
efficient to apply «Exochair» and «ExoAtlant» industrial exoskeletons at workplaces of a logistician working in Sberbank archives and logistics center and a cashier working in the precious metals department of Sberbank Main Cash Center accordingly. Nevertheless, we concluded that it was advisable to make separate reports on safety and efficiency of these industrial exoskeletons being used at workplaces in field conditions taking into account results of the present research, peculiarities existing at workplaces including harmful, and (or) hazardous factors occurring at them, technological process properties, technological operations peculiarities, equipment being used at different workplaces, etc. First of all, it is due to the fact that use of the examined industrial exoskeletons imposes substantial limitations on amplitudes of certain simplest movements and it can produce negative effects on a worker performing some operations as well as result in substantial incon- veniencies in case there is an emergency situation at a workplace.

Several procedures that were used in the present work including functional testing, dynamometry, stabilometry, and psychophysiological testing turned out to be rather unreliable and invalid, and it makes it doubtful that they can be applied in future research.

Procedures that were used in the present work can substantially enrich the existing approaches to examining functional state of workers dealing with physical labor; obtained results can make a substantial contribution into developing a regulatory and technological base for a promising type of personal protective equipment aimed at protecting the musculoskeletal system within the Occupational Safety Standards System.

Funding. The research was not granted any sponsor support.

Conflict of interests. The authors declare there is no any conflict of interests.

\section{References}

1. Lowe B.D., Billotte W.G., Peterson D.R. ASTM F48 Formation and Standards for Industrial Exoskeletons and Exosuits. IISE Transactions on Occupational Ergonomics and Human Factors, 2019, vol. 7, no. 3-4, pp. 7. DOI: $10.1080 / 24725838.2019 .1579769$

2. Ford rolls out exoskeleton wearable technology globally to help lessen worker fatigue, injury. Ford media center, 2018. Available at: https://media.ford.com/content/fordmedia/fna/us/en/news/2018/08/07/fordrolls-out-exoskeleton-wearable-technology-globally-to-help-.html (08.06.2020).

3. Honda Xcelerator to Debut Industrial Innovation Collaborations at CES 2020 Along with New Technologies Coming Soon to Market. Honda. The Power of Dreams, 2019. Available at: https:// hondanews.com/en-US/honda-corporate/releases/release-8d5607d2f6277f4e7a40db54620873de-honda-xcelerator-to-debut-industrial-innovation-collaborations-at-ces-2020-along-with-new-technologies-coming-soonto-market (08.06.2020).

4. Hyundai Develops Wearable Vest Exoskeleton for overhead work. Hyundai Motor Europe, 2019. Available at: https://www.hyundai.news/eu/brand/hyundai-develops-wearable-vest-exoskeleton-for-overhead-work/ (08.06.2020).

5. White Paper: Hip Exoskeleton Market - Review of Lift Assist Wearables. Industry News \& Education, 2018. Available at: http://www.wearablerobotics.com/industry-news-education/ (08.06.2020).

6. Dospekhi dlya rabochego [Armor for a worker]. Kommersant", 2019. Available at: https:// www.kommersant.ru/doc/4088692 (08.06.2020) (in Russian).

7. Anikienko E. Magnitogortsy pokazali ekzoskelet na Nedele mody v Moskve [Experts from Magnitogorsk showed an exoskeleton ay fashion Week in Moscow]. Yuzhnoural'skaya panorama, 2019. Available at: http://up74.ru/articles/news/115137/ (08.06.2020) (in Russian).

8. Kolerova V. Ekzoskelety medlenno idut $\mathrm{v}$ tsekha [Exoskeletons are being introduced in workshops, though rather slowly]. Ekspert, 2018, no. 29. Available at: https://expert.ru/expert/2018/29/ekzoskeletyimedlenno-idut-v-tseha/ (08.06.2020) (in Russian).

9. Priobretenie 30 ekzoskeletov Exorise [Purchase of 30 Exorise exoskeletons]. Tadviser, 2019. Available at: http://www.tadviser.ru/index.php/Проект:Череповецкий_металлургический_комбинат_(ЧерМК)_(Экзоскелеты_Exorise) (08.06.2020) (in Russian). 
10. Schmalz T., J. Schändlinger, Schuler M., Bornmann J. Biomechanical and Metabolic Effectiveness of an Industrial Exoskeleton for Overhead Work. International Journal of Environmental Research and Public Health, 2019, vol. 16, no. 23, pp. 4792. DOI: 10.3390/ijerph16234792

11. Maurice P., Čamernik J., Gorjan D., Schirrmeister B., Bornmann J., Tagliapietra L., Latella C., Pucci D. [et al.]. Objective and Subjective Effects of a Passive Exoskeleton on Overhead Work. IEEE Transactions on Neural Systems and Rehabilitation Engineering, 2020, vol. 28, no. 1, pp. 152-164. DOI: 10.1109/TNSRE.2019.2945368

12. Grimmer M., Quinlivan B.T., Lee S., Malcolm P., Rossi D.M., Siviy C., Walsh C.J. Comparison of the human-exosuit interaction using ankle moment and ankle positive power inspired walking assistance. Journal of Biomechanics, 2019, vol. 83, no. 23, pp. 76-84. DOI: 10.1016/j.jbiomech.2018.11.023

13. Bosch T., Eck J., Knitel K., Looze M. The effects of a passive exoskeleton on muscle activity, discomfort and endurance time in forward bending work. Applied Ergonomics, 2016 vol. 54, pp. 212-217. DOI: 10.1016/j.apergo.2015.12.003

14. Masood J., Dacal-Nieto A., Alonso-Ramos V., Fontano M.I., Voilqué A., Bou J. Industrial Wearable Exoskeletons and Exosuits Assessment Process. Wearable Robotics: Challenges and Trends, vol. 22, pp. 234-238. DOI: 10.1007/978-3-030-01887-0_45

15. Chen G., Wu J., Chen G., Lu Y., Ren W., Xu W., Xu X., Wu Z. [et al.]. Reliability of a portable device for quantifying tone and stiffness of quadriceps femoris and patellar tendon at different knee flexion angles. PLOS ONE, 2019, vol. 14, no. 7. DOI: 10.1371/journal.pone.0220521

16. Lo W.L.A., Yu Q., Mao Y., Li W., Hu Ch., Li L. Lumbar muscles biomechanical characteristics in young people with chronic spinal pain. BMC Musculoskelet Disord, 2019, vol. 23, no. 20 (1), pp. 559. DOI: 10.1186/s12891-019-2935-z

17. Skvortsov D.V. Diagnostika dvigatel'noi patologii instrumental'nymi metodami: analiz pokhodki, stabilometriya: monografiya [Motor pathology diagnostics with instrumental procedures: gait analysis and stabilometry: a monograph]. Moscow, Nauchno-meditsinskaya firma «MBN» Publ., 2007, 640 p. (in Russian).

18. Gamza N.A., Grin' G.R., Zhukova T.V. Funktsional'nye proby v sportivnoi meditsine [Functional tests in sport medicine]. Minsk, Belorusskii gosudarstvennyi universitet fizicheskoi kul'tury Publ., 2012, 57 p. (in Russian).

Geregei A.M., Shitova E.S., Malakhova I.S., Shuporin E.S., Bondaruk E.V., Efimov A.R., Takh V.Kh. Up-to-date techniques for examining safety and physiological efficiency of industrial exoskeletons. Health Risk Analysis, 2020, no. 3, pp. 147-158. DOI: 10.21668/health.risk/2020.3.18.eng

Received: 10.06 .2020

Accepted: 18.08 .2020

Published: 30.09 .2020 